\title{
The overexpression of one single cbh gene making Trichoderma asperellum T-1 a better cellulase producer
}

\author{
Qun Wang ${ }^{1} \cdot$ Liang Chen ${ }^{2} \cdot$ Chengran Fang $^{1} \cdot$ Hua Wang ${ }^{1} \cdot$ Yun Shi $^{1} \cdot$ Yuhua Zhao $^{3}$ (D)
}

Received: 26 November 2018 / Accepted: 26 February 2019 / Published online: 20 March 2019

(C) Università degli studi di Milano 2019

\begin{abstract}
Trichoderma asperellum T-1, a traditional bio-control strain, is previously found to be potentially useful in the degradation of natural waste lignocellulose as it can ferment the natural materials without pretreatment. Many problems caused by substrate pretreatment can be therefore avoided. In this study, we intended to engineer a new strain to enhance its lignocellulose degradation ability by modifying the genome of $T$. asperellum T-1. A genetic transformation system mediated by Agrobacterium tumefaciens AGL-1 (ATMT) was constructed on T. asperellum T-1. On this basis, the overexpressed strain was produced by transforming a recombinant cellobiosidase gene $(c b h)$ under the control of inducible promoter of endo-1, 4- $\beta$-xylanase gene, into wild-type T. asperellum T-1. After resistance screening, multiple transmission, growth comparison, and enzyme activity determination, four transformants (M1, M2, M5, and M6) were obtained. Filter paper cellulase activity of these transformants reached, respectively, 36.2\%, 30.6\%, 32.9\%, and $42.7 \%$ higher than the wild-type strain. Most importantly, the CMCase, $\beta$-glucosidase and xylanase activity were also increased, although only one $c b h$ gene was overexpressed. This work indicated that the enhancement of cellulase production ability of $T$. asperellum T-1 can be promisingly feasible by genetic modification. And the xylanase gene's promoter can be effectively used in genetic modification to promote T. asperellum T-1 to be more effectively used in lignocellulose degradation.
\end{abstract}

Keywords T. asperellum T-1 $\cdot$ ATMT $\cdot$ Cellulase activity $\cdot$ Cellobiosidase gene $\cdot$ Xylanase gene promoter

\section{Introduction}

Under the background of the increasing shortage of non-renewable fuels, agricultural wastes existing in nature have already become the most important resources

Electronic supplementary material The online version of this article (https://doi.org/10.1007/s13213-019-01458-7) contains supplementary material, which is available to authorized users.

\footnotetext{
Chengran Fang

fangchengr@163.com

$\triangle$ Yuhua Zhao

microbeapply@zju.edu.cn

1 Key Laboratory of Recycling and Eco-treatment of Waste Biomass of Zhejiang Province, Zhejiang University of Science and Technology, Hangzhou 310023, China

2 Zhejiang Gongshang University, Hangzhou 310018, China

3 College of Life Sciences, Zhejiang University, Hangzhou 310058, China
}

for obtaining fermentable sugars as substrates for production of biofuel. Through microbial fermentation, different kinds of waste lignocelluloses can be degraded and further converted into acids, hydrocarbons, and their derivatives, such as biodiesel (Inoue et al. 2016; Xiong et al. 2018). These lignocellulose materials mainly consist of cellulose, hemicellulose, and lignin. Among them, cellulose, accounting for $35-50 \%$ of lignocelluloses, is the main source of fermentable sugars (Daeseok et al. 2014). The bioconversion of lignocellulosic wastes to fermentable sugars is the essential step for biofuel production (Kuhad et al. 2011). However, because of diversity of nature cellulose resources, complexity of multi-components, and intrinsic recalcitrance of plant cell walls, this process is much restricted (Margeot et al. 2009). And untreated lignocellulosic wastes are difficult to be degraded directly by microbial enzymes.

The traditional lignocellulose transformation process always includes substrate pretreatment and microbial 
transformation. After pretreatment, the natural structure of the lignocellulose is destroyed; the substrates can be reached and then saccharified by microbial cellulase (Ding and Bayer 2012). However, the disadvantages of pretreatment, such as the complexity of the operation, the necessity for strictly controlled conditions, and the consequence of secondary pollution, cannot be ignored (Kubicek et al. 2009). Moreover, the toxic factors produced in the chemical pretreatment process may greatly inhibit the microbial metabolism (Kim et al. 2003a). Therefore, the isolation of new microorganisms with the ability of degrading natural lignocellulose without pretreatment is of great significance.

Filamentous fungi are the main decomposers of lignocellulosic biomasses, which enable them to penetrate plant tissues (Singhania et al. 2009; Boer et al. 2010). Enzymes produced by Trichoderma spp. have been investigated for the decomposition of different kinds of substrates, such as wheat straw (Alvira et al. 2013), corn stover (Rana et al. 2014), and rice straw (Zhang et al. 2009; Kogo et al. 2017). In our previous research, a strain of Trichoderma asperellum, named T-1, was found to be able to secrete cellulase with enhanced hydrolysis abilities. Most importantly, this strain can ferment the natural materials without pretreatment, showing a great potential in the degradation of natural waste lignocellulosic material (Wang et al. 2015; Wang et al. 2017). Studies about $T$. asperellum have reported its potential in glycoside hydrolase $(\mathrm{GH})$ production, and those hydrolases can degrade the carbohydrates in the plant cell walls to release bioactive polymers, proteins, and simple sugars (Selvamani et al. 2015).

Even the excellent waste biomass-degrading performance of $T$. asperellum $\mathrm{T}-1$ has been investigated in our previous research by comparison with Trichoderma reesei QM6a (Wang et al. 2017); it was also found that the filter paper cellulase activity, which can reflect the total activity of cellulose, was relatively weak. As an effective biological control species against many pathogenic microorganisms, T. asperellum received considerable attention (Keswani et al. 2014). So far, most published genetic modification studies about $T$. asperellum always focused on its biological control functions and aimed to explore the mechanism of reducing plant disease (Zhang et al. 2015; Ji et al. 2016). And there are few reports on improving cellulase activity of T. asperellum by using genetic modification. Among the limited publications, most are about the cloning and in vitro expression of single cellulase gene (Marcello et al. 2010; Bech et al. 2015), or intend to obtain high-yield cellulase mutants by physical mutagenesis (Raghuwanshi et al. 2014). Therefore, this research aims to firstly construct an effective genetic transformation mediated by Agrobacterium tumefaciens AGL-1 and then to improve the cellulase activity of T. asperellum T-1 using molecular biological methods.

\section{Materials and methods}

\section{Strains and pretreatment of wheat straw}

Trichoderma asperellum T-1 (GenBank: KM277355) was isolated from African jungle soil samples collected from the Republic of Cameroon. Agrobacterium tumefaciens AGL-1 was stored at $-80^{\circ} \mathrm{C}$ with $30 \%$ sterile glycerin and revitalized in the LB plates containing kanamycin $\left(60 \mu \mathrm{g} \mathrm{mL}^{-1}\right)$.

Wheat straw, collected from Bozhou city, Anhui province (GPS coordinates: 33.923136, 115.83361), was dried before milling through sifters to ensure that the particle diameter was $75-154 \mu \mathrm{m}$.

\section{Sensitivity of T. asperellum T-1 to hygromycin B}

The concentration of hygromycin B ranging from $100 \mu \mathrm{g} \mathrm{mL}^{-1}$ to $300 \mu \mathrm{g} \mathrm{mL}{ }^{-1}$ was used for testing the antibiotic resistance of $T$. asperellum $\mathrm{T}-1$. Trichoderma asperellum $\mathrm{T}-1$ was firstly inoculated on PDA plates at $28^{\circ} \mathrm{C}$ for 5 days. Spores were subsequently harvested and washed once by $0.1 \%(v / v)$ Tween 80 . Next, the obtained spores were suspended in sterile water. Twenty microliters spore suspension $\left(10^{6}\right.$ spores $\left.\mathrm{mL}^{-1}\right)$ was spread on PDA plate containing different concentrations of hygromycin $\mathrm{B}$ and incubated at $28{ }^{\circ} \mathrm{C}$. The growth of the mycelium over time was observed and recorded.

\section{Plasmid construction}

Firstly, to obtain the nucleotide acid sequence of cellobiohydrolase gene $(c b h)$ in $T$. asperellum T-1, the sequence of $c b h 1$ gene of T. reesei QM6a (Gene ID: 1848279) was used as the probe sequence to search for target homologous information in the genomic sequence of $T$. asperellum in JGI database (http://genome.jgi.doe.gov/pages/search-forgenes.jsf?organism $=$ Trias 1 ). Primers were designed accordingly and then $c b h$ gene in $T$. asperellum T-1 was amplified by the polymerase chain reaction (PCR).

The construction procedure of the recombinant expression vector for T. asperellum $\mathrm{T}-1$ is shown in Fig. 1. pKO1 vector was used as the original plasmid and its primary structure is given in Fig. S1. The amplified hygromycin resistance gene $(h p h)$ was inserted into the Xhol/SacI sites of pKO1. The $c b h$ gene was expressed under the control of the promoter of endo1, 4- $\beta$-xylanase gene (Pxyl) from T. asperellum T-1. Pxyl + $c b h$ fragment was obtained by overlapping PCR and then inserted into the SacI/HindIII sites of $\mathrm{pKO} 1+h p h$ vector. Primers used here are shown in Table S1. Nucleotide sequences of the constructed plasmid were sequenced in Shanghai Sangon Co., Ltd. 
Fig. 1 Construction procedure of the recombinant expression vector for T. asperellum T-1
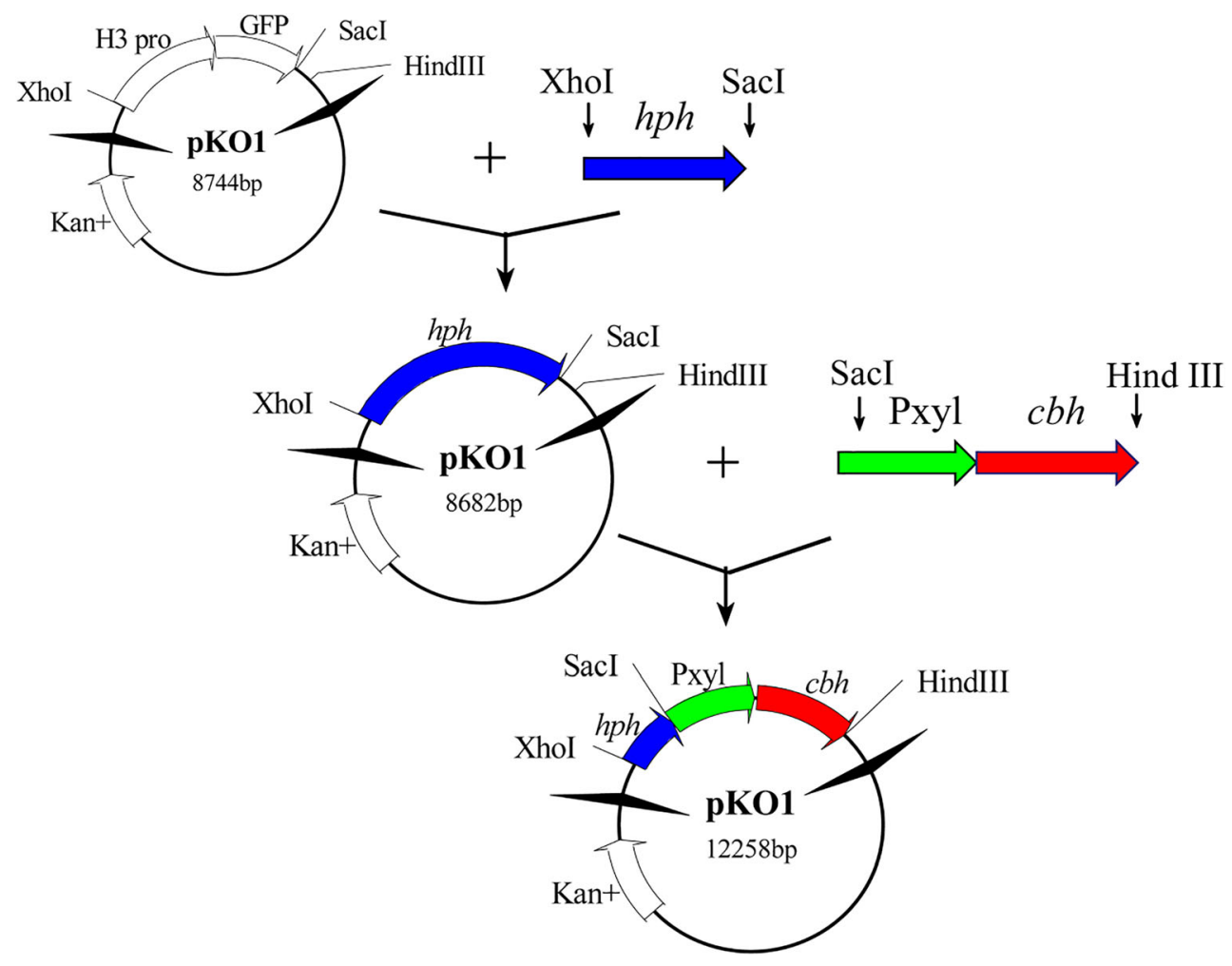

\section{A. tumefaciens AGL-1-mediated transformation}

Trichoderma asperellum T-1 was cultivated on PDA for 46 days at $28^{\circ} \mathrm{C}$, and then the spores were harvested and transformed with the constructed plasmid mediated by A. tumefaciens AGL-1 according to a previously reported procedure (Liang et al. 2015). After a cocultivation of T. asperellum T-1 and A. tumefaciens AGL-1, the nitrocellulose membrane strips with mycelium were transferred to AIM medium and cultivated in the dark at $22{ }^{\circ} \mathrm{C}$ for 2 days. Then, the strips were transferred onto PDA plates containing $200 \mu \mathrm{g} \mathrm{mL}^{-1}$ homomycin $\mathrm{B}, 50 \mu \mathrm{g} \mathrm{mL} \mathrm{mL}^{-1}$ kanamycin, $400 \mu \mathrm{g} \mathrm{mL}^{-1}$ cefotaxime, and $60 \mu \mathrm{g} \mathrm{mL}^{-1}$ streptomycin. The resistant transformants were individually transferred onto new PDA plates using sterile toothpicks. The transformants able to grow well on PDA plate containing $200 \mu \mathrm{g} \mathrm{mL}{ }^{-1}$ hygromycin B after 5 or more serial subcultivation without recession were kept for further analysis.

\section{Screening for positive transformants}

Congo red staining was used to primarily screen for the positive transformants. Specifically, the transformants were inoculated into sodium carboxymethyl cellulose plates, cultured at $28^{\circ} \mathrm{C}$ for 3 days. The mycelium on the medium was scraped lightly with the coating rod and then $10 \mathrm{~mL}$ Congo red solution $(0.2 \%, w / v)$ was added onto the plate. After $30 \mathrm{~min}$, the dye solution was discarded. Finally, $\mathrm{NaCl}$ solution (1 M) and distilled water were used to wash the residual dye away. The diameters of the transparent circles were measured and recorded.

The genomic DNA of 30 randomly selected transformants and the wild-type strain were extracted according to CTAB method (Rogers and Bendich 1994). PCR was used to confirm the existence of the inserted DNA fragments including the $h p h$ gene, $P x y l, c b h$ gene, and the combined $h p h+P x y l+c b h$. The primers used here are shown in Table S2.

\section{Growth of positive transformants}

Ten strains of the above positive transformants and the wildtype $T$. asperellum T-1 were inoculated on hygromycin Bcontaining PDA plates at $28^{\circ} \mathrm{C}$ for 3 days. Then, the mycelium together with the agar was punctured using a 5-mm sterilized cork borer and then transferred onto the center of new PDA plates without hygromycin B for cultivation at $28{ }^{\circ} \mathrm{C}$. The colony diameter at $20 \mathrm{~h}, 38 \mathrm{~h}$, and $50 \mathrm{~h}$ of the cultivation was measured.

Spores were subsequently harvested, washed once by $0.1 \%$ $(v / v)$ Tween 80 , and suspended in sterile water. Spores of T. asperellum T-1 were inoculated into $100 \mathrm{~mL}$ of PDB medium at a final concentration of $10^{6}$ spores $\mathrm{mL}^{-1}$, and the growth of the hypha was recorded. After the liquid culture, the mycelium was obtained by centrifugation and then dried at $70{ }^{\circ} \mathrm{C}$ for 5 days. The accumulated biomass was then weighted. 


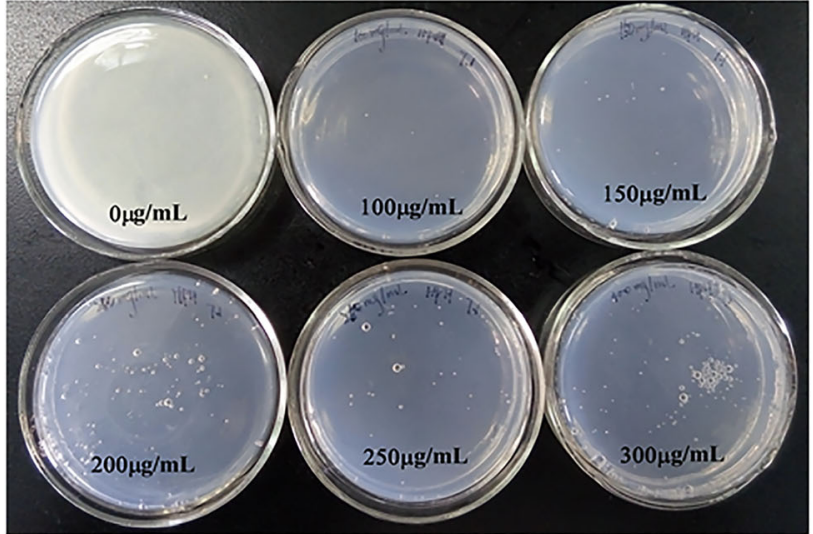

2days

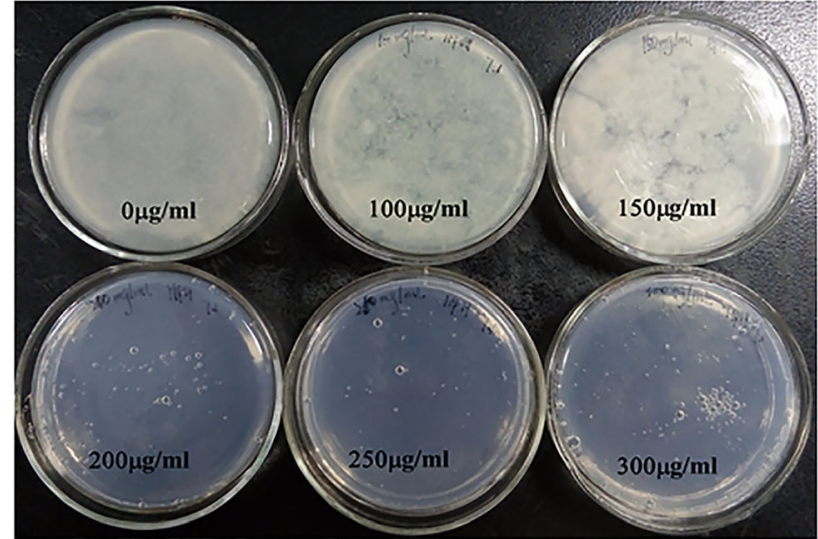

5days

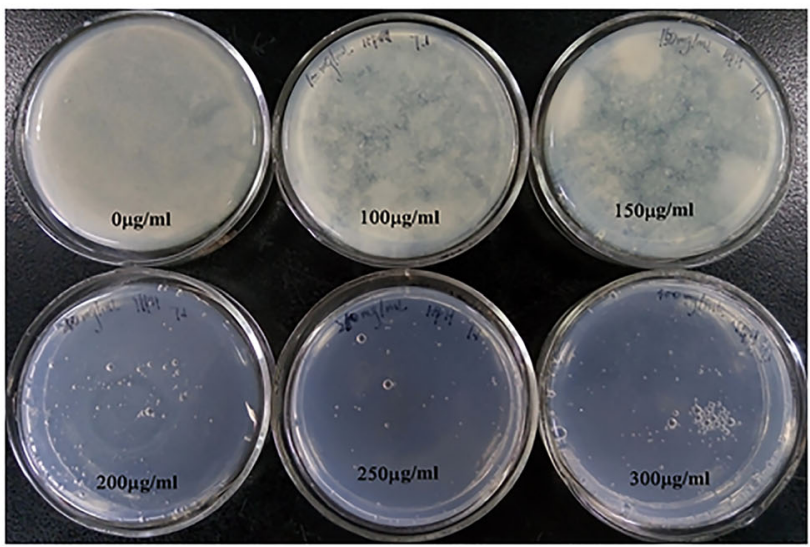

8days

Fig. 2 Cell growth of T. asperellum T-1 on PDA plate containing different concentrations of hygromycin B

\section{Fermentation and enzyme activity assay}

Spores of $T$. asperellum $\mathrm{T}-1$ were inoculated into $100 \mathrm{~mL}$ of basal medium [in $\mathrm{g} \mathrm{L}^{-1}: \mathrm{KH}_{2} \mathrm{PO}_{4}, 2.0$; $\left(\mathrm{NH}_{4}\right)_{2} \mathrm{SO}_{4}, 1.4 ; \mathrm{MgSO}_{4} \cdot 7 \mathrm{H}_{2} \mathrm{O}, 0.3 ; \mathrm{CaCl}_{2}, 0.3 ; \mathrm{FeSO}_{4}$. $7 \mathrm{H}_{2} \mathrm{O}, 0.005 ; \mathrm{MnSO}_{4} \cdot \mathrm{H}_{2} \mathrm{O}, 0.00156 ; \mathrm{ZnSO}_{4} \cdot 7 \mathrm{H}_{2} \mathrm{O}$, $0.0014 ; \mathrm{CoCl}_{2}, 0.002$; urea, 0.3 ; $\left.\mathrm{pH} 5.5\right]$ at a final concentration of $10^{6}$ spores $\mathrm{mL}^{-1}$. One percent of the wheat straw $(w / v)$ was used as carbon sources. Next, the triangular flasks were shaken at $200 \mathrm{rpm}$ and $28{ }^{\circ} \mathrm{C}$. One milliliter of fermentation liquor was taken from each triangular flask at days $4,8,12$, and 16 . After centrifugation at $12,000 \mathrm{rpm}$ for $1 \mathrm{~min}$, the supernatant was collected and stored at $-20{ }^{\circ} \mathrm{C}$. Filter paper cellulase activity (FPase), endoglucanase activity (CMCase), $\beta$ glucosidase activity, and xylanase activity were analyzed using the previously reported method (Wang et al. 2017). All of the fermentation experiments were performed in triplicates, and the obtained samples were further analyzed in triplicates.

\section{Data analysis}

All reported data are the average values of at least three duplicates. Statistical inferences were calculated using one-way analysis of variance (SigmaPlot version 12.5).

\section{Results and discussion}

\section{Construction of the genetic transformation system of $T$. asperellum T-1}

As an efficient transformation method, genetic transformation mediated by A. tumefaciens has been used in the genetic modification of many organisms including fungal, plant, and mammalian cells (Bundock et al. 1995; Rho et al. 2011; Florencio et al. 2018). For filamentous fungi, the most important advantage of ATMT compared to other conventional transformation methods is the availability of different kinds of starting bio-sample, including hyphae, spores, and 
Fig. 3 Congo red staining of the wild-type T. asperellum T-1 (CK) and its mutant cultivated on carboxymethyl cellulose plates
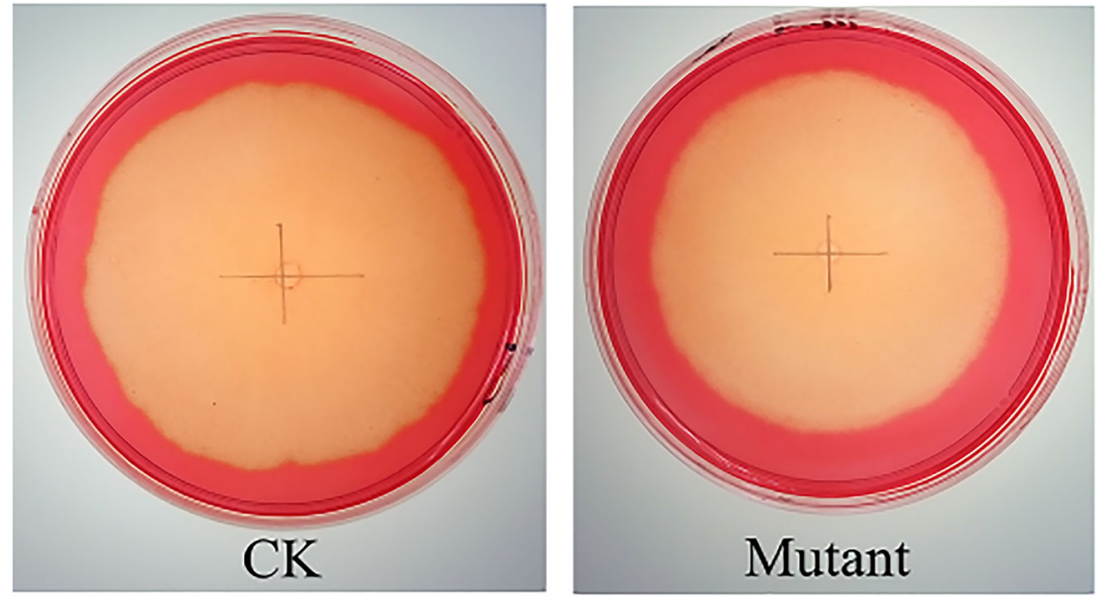

protoplasts (Michielse et al. 2008). Agrobacterium is a kind of gram-negative soil bacterium which can transfer the DNA (TDNA) located on Ti-plasmid to random sites into the genome of the target cells (Zambryski 1988; Florencio et al. 2018). And due to the easy operability and high efficiency, ATMT is considered to be a popular tool for random insertion mutagenesis to construct a mutant library (Nakamura et al. 2012).

In order to construct a transformation system for genetic manipulation, it is necessary to screen an antibiotic exhibiting effective inhibition on strain growth. Hygromycin B, a kind of aminoglycoside antibiotic produced by Streptomyces hygroscopious, is widely used in transformants screening for its advantage of less false positive transformants and good experiment repeatability. In this study, we measured the sensitivity of T. asperellum $\mathrm{T}-1$ to hygromycin $\mathrm{B}$ and the results are shown in Fig. 2. As shown, T. asperellum T-1 grew well on hygromycin B-free plates. After 2 days of culture, white hyphae were visible on PDA plates, while no obvious mycelium was observed on hygromycin B-containing plates. As the incubation time increased, mycelium appeared on PDA plates when the hygromycin $\mathrm{B}$ concentration was $100 \mu \mathrm{g} \mathrm{mL}^{-1}$ or

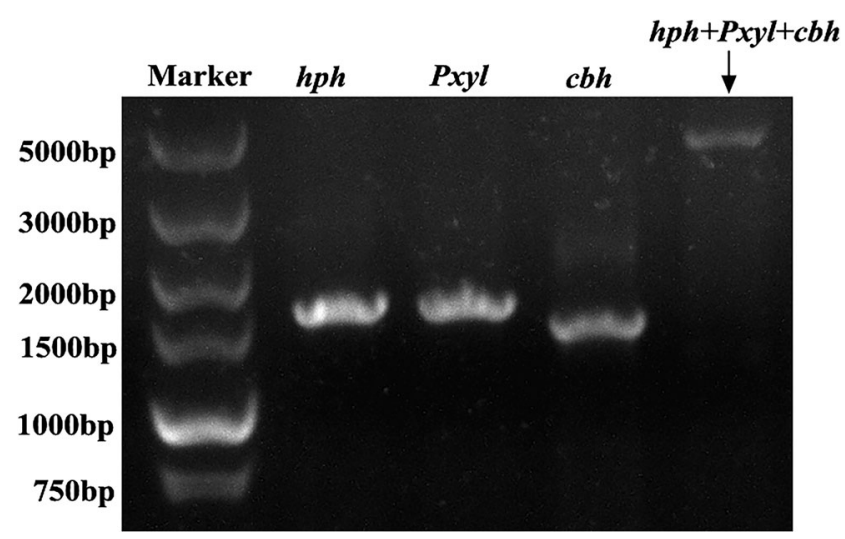

Fig. 4 Detection of $h p h, P x y l, c b h$, and $h p h+P x y l+c b h$ fragment on the genome of the positive transformants by PCR
$150 \mu \mathrm{g} \mathrm{mL}^{-1}$. After the concentration of hygromycin B increased to $200 \mu \mathrm{g} \mathrm{mL}^{-1}$, the growth of T. asperellum $\mathrm{T}-1$ was totally inhibited. This result suggests that hygromycin B could be used as a resistance antibiotic for the construction of the genetic transformation system of $T$. asperellum $\mathrm{T}-1$, and the lowest concentration should be $200 \mu \mathrm{g} \mathrm{mL}^{-1}$.

The level of gene expression in filamentous fungi is closely related to the gene promoter (Gouka et al. 1997). Previous study found that $T$. asperellum $\mathrm{T}-1$ could largely secrete $\beta-1$, 4-endoxylanase (Wang et al. 2015), a kind of cellulase that cleaves the $\beta$-(1,4)- glycosidic bonds between xylose units in the xylan backbone to produce xylo-oligosaccharides. Moreover, both Bech et al. (2015) and Marx et al. (2013) separately reported that xylanase secreted by $T$. asperellum could be exploited for important industrial processes as an important component enzyme. The promoter of the xylanase gene is a typical inducible strong promoter, which has been used to promote the expression of cellulase genes (Rahman et al. 2009).

Table 1 Colony diameters of T. asperellum T-1 and transformants on antibiotic-free PDA plates

\begin{tabular}{llll}
\hline Strains & \multicolumn{2}{l}{ colony diameter $(\mathrm{cm})$} \\
\cline { 2 - 4 } & $20 \mathrm{~h}$ & $38 \mathrm{~h}$ & $50 \mathrm{~h}$ \\
\hline M1 & $2.13 \pm 0.05$ & $4.83 \pm 0.05$ & $6.30 \pm 0.14$ \\
M2 & $2.18 \pm 0.05$ & $4.90 \pm 0.00$ & $6.48 \pm 0.05$ \\
M3 & $1.85 \pm 0.10$ & $4.55 \pm 0.06$ & $5.98 \pm 0.05$ \\
M4 & $2.28 \pm 0.05$ & $4.93 \pm 0.05$ & $6.40 \pm 0.00$ \\
M5 & $1.88 \pm 0.05$ & $4.55 \pm 0.13$ & $6.05 \pm 0.10$ \\
M6 & $2.03 \pm 0.15$ & $4.60 \pm 0.12$ & $6.10 \pm 0.14$ \\
M7 & $2.40 \pm 0.14$ & $4.98 \pm 0.10$ & $6.45 \pm 0.10$ \\
M8 & $1.88 \pm 0.05$ & $4.40 \pm 0.08$ & $5.93 \pm 0.10$ \\
M9 & $1.98 \pm 0.05$ & $4.60 \pm 0.12$ & $6.08 \pm 0.17$ \\
M10 & $2.55 \pm 0.06$ & $5.15 \pm 0.06$ & $6.60 \pm 0.08$ \\
CK & $2.38 \pm 0.15$ & $5.28 \pm 0.21$ & $6.65 \pm 0.21$ \\
\hline
\end{tabular}


The advantage of an inducible promoter is that the expression of downstream genes is only initiated when there is a refractory substrate in the environment, avoiding unnecessary cell metabolism (Vicent et al. 2004). Therefore, we selected the promoter of $\beta-1,4$-xylanase gene of $T$. asperellum $\mathrm{T}-1$ to mediate the overexpression of $c b h$ gene, which can not only ensure the expression intensity of the target gene but also avoid instability caused by heterologous expression of the gene.

As mentioned above, our previous research has found that even the waste biomass-degrading performance of T. asperellum T-1 was excellent, and the filter paper cellulase activity was relatively weak (Wang et al. 2015). The major cellulases involved in lignocellulose degradation are known to include cellobiohydrolase, $\beta$-glucosidase, xylanase, and carboxymethyl cellulase. As it was also found in our previous research that the $\beta$-glucosidase activity, xylanase activity, and carboxymethyl cellulase activity of $T$. asperellum T-1 were actually high (Wang et al. 2017), it could be indicated that the relatively weak filter paper cellulase activity might be caused by the insufficient secretion of cellobiohydrolase. Thus, we chose the $c b h$ gene to be overexpressed to improve the cellulase production of $T$. asperellum $\mathrm{T}-1$.

In accordance with the procedure in Fig. 1, the hph gene, Pxyl promoter, and $c b h$ gene were inserted into $\mathrm{pKO} 1$ vector. And the overexpression vector $(\mathrm{pKO} 1-h p h+P x y l+c b h)$ with hygromycin B resistance as a marker was successfully constructed. The recombinant vector was successfully transformed into T. asperellum T-1 using ATMT method. After more than five subcultures, the transformants which could grow well on the PDA medium containing $200 \mu \mathrm{g} \mathrm{mL}$ hygromycin B were kept.

\section{Screening for the positive transformants of $T$. asperellum T-1}

Random insertion of DNA fragments may disrupt the expression of some original genes of the strain, leading to changes in the metabolic characteristics (Dmytruk et al. 2006). Thus, we firstly used the method of Congo red staining to screen for the transformants whose cellulase activity was not destroyed (Béguin 1983). After that, 23 strains of the transformants were obtained. As shown in Fig. 3, cellulase hydrolysis circle obviously appeared on plates of target transformants; the circle diameter of the transformants and the wild-type T. asperellum T-1 were similar. Specifically, circle diameter of the wild-type T. asperellum T-1 was $8.0 \pm 0.2 \mathrm{~cm}$, and the circle diameters of all the transformants were ranging from $7.8 \pm 0.3 \mathrm{~cm}$ to $8.3 \pm$ $0.2 \mathrm{~cm}$. Although results of Congo red staining indicated that the transformants still retained a high cellulose degradation ability, further verification and analysis of the transformed strains by molecular method are indispensable.

In order to verify the existence of $h p h, P x y l$, and $c b h$ and whether $h p h+P x y l+c b h$ fragment was correctly inserted into the genome of transformants, particularly to make sure whether the $c b h$ gene was within the regulatory range of the Pxyl promoter, we designed primers based on the target fragment for PCR amplification (Table S2). As shown in Fig. 4, the hph gene, the Pxyl promoter, and the $c b h$ gene could be simultaneously amplified in the positive transformants, and the combined sequence $h p h+P x y l+c b h$ was intact, indicating that the $c b h$ gene was under the control of the $\beta-1,4$-xylanase gene's promoter. Subsequently, we selected 10 of the positive transformants for the following studies.

\section{Cell growth of $T$. asperellum T-1 transformants}

The colony diameters of the wild-type $T$. asperellum T-1 and 10 transformants growing on antibiotic-free PDA plates were measured. Meanwhile, the growth of mycelium and biomass accumulation during the liquid culture were observed and measured after 3 days of culture at $28^{\circ} \mathrm{C}$. As Table 1 shows, the colony diameters of most transformants were a little smaller than that of the wild-type $T$. asperellum T-1 during the plate culture. Both Fig. 5 and Table 2 showed that the growth of different strains was quite different from each other during the liquid culture. The mycelium accumulation of the wild-type strain in the liquid medium was the largest, and the growth of the transformants was weaker than that of the wild-type strain.

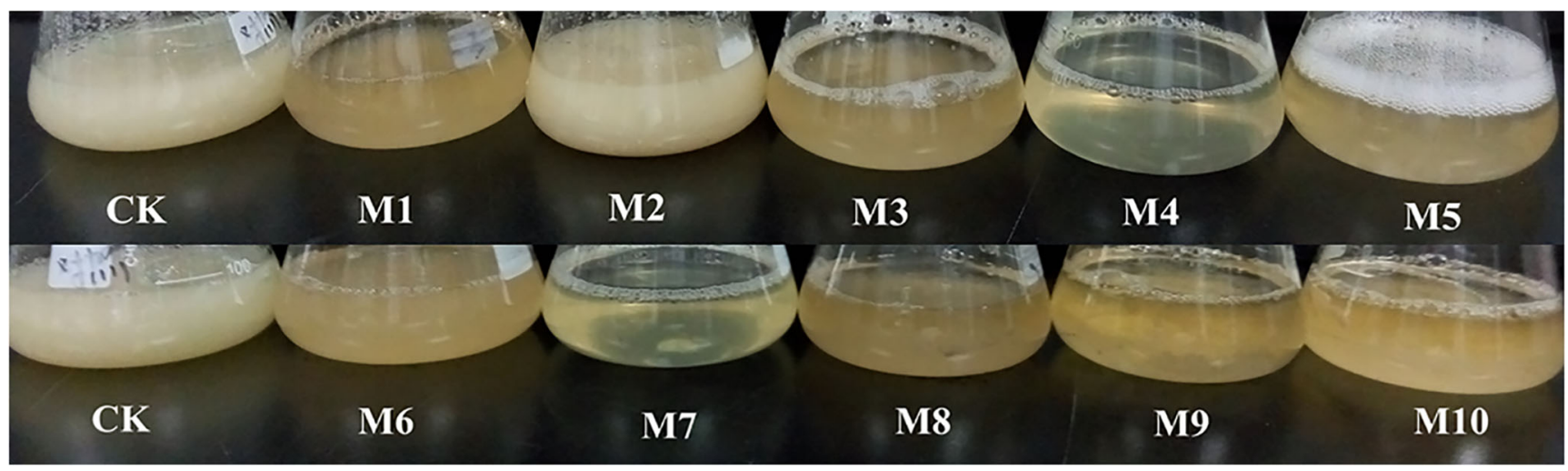

Fig. 5 Growth of T. asperellum T-1 and its transformants in liquid cultivation 


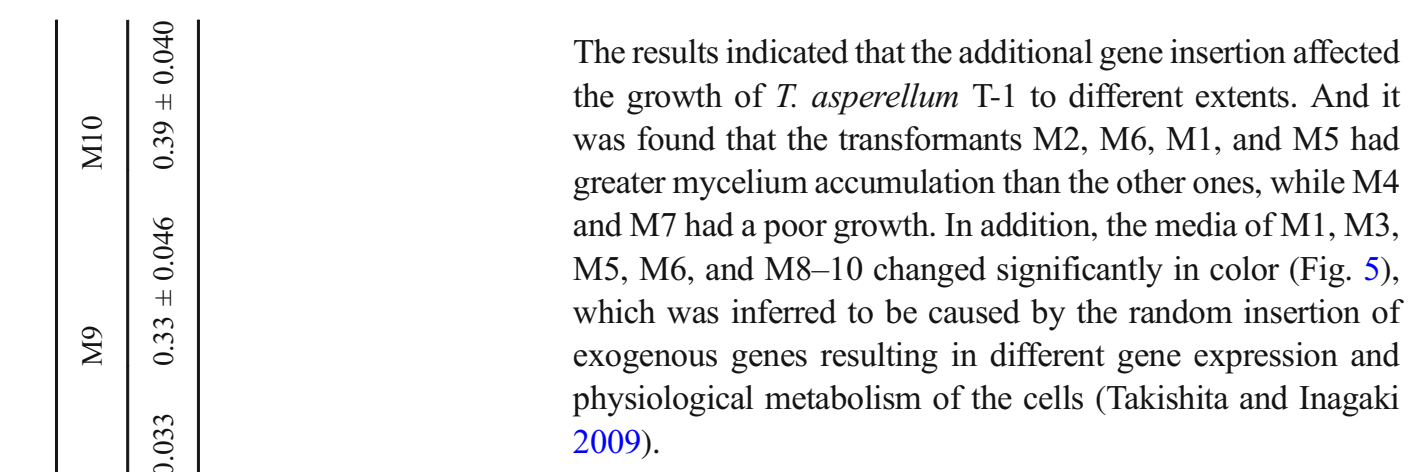

\section{Comparison of FPase activity between $T$. asperellum} $\mathrm{T}-1$ and transformants

The effective hydrolysis of lignocellulose material is attributed to at least three kinds of enzymes, including endoglucanases, exoglucanases, and $\beta$-glucosidases. The first ones initiate the hydrolysis, release different-sized oligosaccharides, and expose reductive and non-reductive ends accessible for exoglucanases; the second ones attack these terminations to liberate cellobiose and cellooligosaccharides; while $\beta$ glucosidases finally hydrolyze cellobiose and other cellodextrins to the desired glucose (Sukumaran et al. 2009; Gottschalk et al. 2010; Bansal et al. 2011; Deswal et al. 2011). Nowadays, the interest in producing cellulases using waste biomass is increasing. Previous researches have shown the capacity of $T$. asperellum to degrade a complex matrix of cellulose, such as Agave atrovirens fibers (Nava-Cruz et al. 2016), rice straw and switch grass (Wang et al. 2017). In the present work, we aimed to construct a genetic transformation system mediated by A. tumefaciens AGL-1 and to further enhance the cellulose enzymatic activity of T. asperellum T1 by overexpressing the exocellulase gene $(c b h)$. According to the cell growth and biomass accumulation, we chose M1, M2, M5, and M6 to be used in the fermentation with wheat straw as substrate. The enzyme activities of different transformants were compared with the wild-type $T$. asperellum $\mathrm{T}-1$.

FPase can most accurately reflect the lignocellulose degradation ability, since filter paper is highly crystalline cellulose (Vincken et al. 1994; Teeri 1997). Figure 6 showed the FPase of the wild-type T. asperellum T-1 and its mutants M1, M2, M5, and M6. It was obvious that the FPase of all the mutants were higher than that of the wild-type T. asperellum T-1. Specifically, the FPase activity of M1, M2, M5, and M6 reached respectively $36.2 \%, 30.6 \%, 32.9 \%$, and $42.7 \%$ higher than the wild-type strain. In previous report, Lin et al. engineered Aspergillus oryzae A-4 through the chromosomal insertion of several foreign cellulase expression cassettes and improved the FPase activity of the transformants by 22.69 $59.42 \%$ (Hui et al. 2014). However, the genetic transformation method used in that research was protoplast transformation, which has very low conversion efficiency, tedious operation process, and stringent experimental conditions (Kubodera 


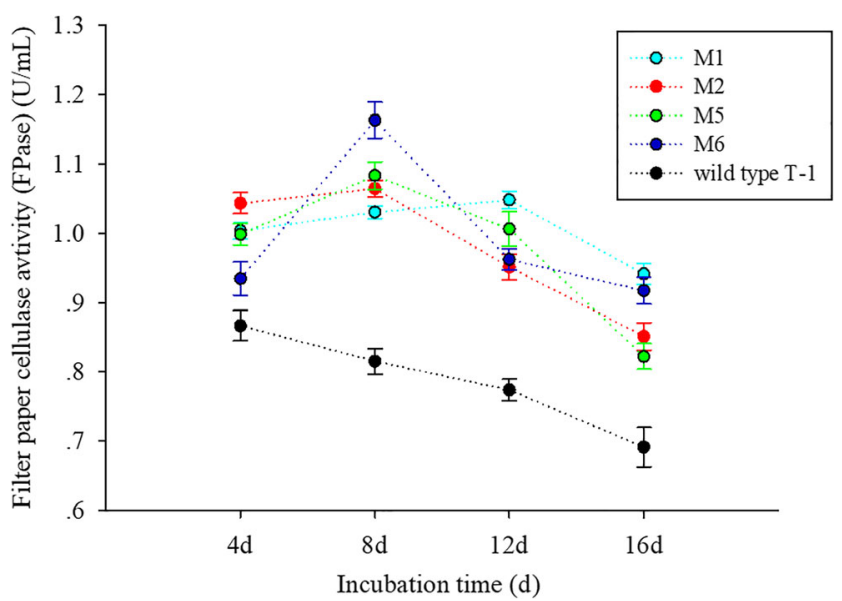

Fig. 6 FPase of the wild-type T. asperellum T-1 and its transformants M1, M2, M5, M6

et al. 2002). And although the hlyA promoter would not be repressed by glucose and can effectively initiate a large amount of gene expression, as a kind of constitutive promoter, it caused the reduced cell growth as cellulase expression is unnecessary for the cell growth when the carbon source is not lignocellulose (Sharma and Mutharasan 2013). The metabolic burdens imposed on host strains by the overexpression of foreign proteins have been previously reported by many researchers (Kim et al. 2003b; Rensburg et al. 2012). Here in this research, we used the homologous and inducible promoter of $T$. asperellum $\mathrm{T}-1$; therefore, the downstream genes would be initiated only when the carbon source was lignocellulose. More importantly, the cellulase activity of the T. asperellum $\mathrm{T}-1$ in this study was increased significantly by overexpressing only one $c b h$ gene.

\section{Cellulase production characterization of the $T$. asperellum strains after mutation}

So far, there are few studies on the genetic modification of T. asperellum for the purpose of enhancing its lignocellulose degradation ability. In previous report, a mutant strain of T. asperellum RCK2011 has been developed through UVirradiation with enhanced cellulase production. The FPase, CMCase, and $\beta$-glucosidase activity of the mutant strain T. asperellum SR1-7 reached 1.4, 1.3, and 1.5-fold higher than the wild-type repression produced under optimized conditions (Raghuwanshi et al. 2014). Here in this research, we also analyzed the CMCase, $\beta$-glucosidase, and xylanase activity of the mutants M1, M2, M5, and M6 by comparing with the wild-type $T$. asperellum $\mathrm{T}-1$ and the reported strains (Table 3). Firstly, it was obvious that the cellulase activity of the wild-type strain T. asperellum $\mathrm{T}-1$ was high than that of the wild-type strain RCK2011. However, as the lignocellulosic enzyme series secreted by fungi is known to depend on the type and composition of the carbon source and the way of fermentation, it cannot be directly concluded that T. asperellum $\mathrm{T}-1$ has a better cellulase production ability than strain RCK2011 (Nurul Kartini et al. 2012; Marx et al. 2013). As shown in Table 3, the overexpression of the $c b h$ gene enhanced the activity of FPase greatly, and the CMCase, $\beta$ glucosidase, and xylanase activity of the most transformants were also increased. In other words, although only one $c b h$ gene was overexpressed, the CMCase, $\beta$-glucosidase, and xylanase activity in addition to FPase were all improved. As mentioned above, cellobiosidases $(c b h)$, also known as exoglucanases, attack the terminations of the linear polymer of glucose to liberate cellobiose and cellooligosaccharides (Gusakov 2011). The main inducer of cellulase gene expression is the degradation product of lignocellulose, while cellobiose is one of the most important inducers (Znameroski et al. 2012). In our research, the overexpression of $c b h$ gene might result in the more release of cellobiose, which could further induce the expression of cellulase genes. And this is probably the main reason for the increase of the other cellulase activities except FPase in this research.

As previously reported, T. asperellum $\mathrm{T}-1$ had a better cellulose degradation ability in the early stage of the fermentation, and then the cellulase activity started to decrease (Wang

Table 3 FPase, CMCase, $\beta$-glucosidase, and xylanase activities of M1, M2, M5, and M6 compared with the wild-type strain T-1 and the reported strains

\begin{tabular}{|c|c|c|c|c|c|c|c|}
\hline Strains & Substrate & Fermentation & $\begin{array}{l}\text { FPase } \\
(\mathrm{IU} / \mathrm{g})\end{array}$ & $\begin{array}{l}\text { CMCase } \\
(\mathrm{IU} / \mathrm{g})\end{array}$ & $\begin{array}{l}\beta \text {-glucosidase } \\
(\mathrm{IU} / \mathrm{g})\end{array}$ & $\begin{array}{l}\text { Xylanase } \\
\text { (IU/g) }\end{array}$ & Reference \\
\hline T. asperellum T-1 (wild) & WS & $\mathrm{SmF}$ & $0.882 \pm 0.054$ & $7.541 \pm 0.257$ & $10.534 \pm 0.154$ & $14.562 \pm 0.735$ & Present work \\
\hline$M 1$ & & & $1.201 \pm 0.068$ & $9.049 \pm 0.133$ & $13.467 \pm 0.054$ & $12.364 \pm 0.556$ & \\
\hline$M 2$ & & & $1.152 \pm 0.034$ & $7.445 \pm 0.251$ & $10.045 \pm 0.253$ & $15.882 \pm 0.475$ & \\
\hline M5 & & & $1.172 \pm 0.069$ & $8.762 \pm 0.147$ & $11.655 \pm 0.112$ & $13.236 \pm 0.764$ & \\
\hline M6 & & & $1.259 \pm 0.043$ & $9.879 \pm 0.141$ & $15.795 \pm 0.321$ & $1.892 \pm 0.347$ & \\
\hline T. asperellum RCK2011 (wild) & WS & SSF & $0.736 \pm 0.069$ & $4.449 \pm 0.226$ & $11.001 \pm 0.24$ & - & Raghuwanshi et al. (2014) \\
\hline T. asperellum SR7 (Mutant) & & & $0.711 \pm 0.047$ & $6.301 \pm 0.022$ & $12.013 \pm 0.15$ & - & \\
\hline T. asperellum RCK2011 (wild) & WB & SSF & $0.613 \pm 0.001$ & $2.741 \pm 0.133$ & $4.255 \pm 0.011$ & - & \\
\hline T. asperellum SR7 (mutant) & & & $1.013 \pm 0.013$ & $6.394 \pm 0.442$ & $10.290 \pm 0.157$ & - & \\
\hline
\end{tabular}

$W S$ wheat straw; $W B$ wheat bran; $S m F$ submerged fermentation; $S S F$ solid-state fermentation 
et al. 2015). Accordingly, the FPase of the wild-type T. asperellum T-1 shown in Fig. 6 had already decreased from the 4th day, while the FPase of the transformants decreased from the 8th (M2, M5 and M6) or 12th (M1) day of the fermentation. This result was consistent with the research of Sanjeev Raghuwanshi et al. that both the wild-type RCK2011 and the mutant SR1-7 released cellulases within $48 \mathrm{~h}$ of incubation and exhibited maximum cellulase activity on from 4th to 7th day of incubation (Raghuwanshi et al. 2014). Actually, because T. asperellum $\mathrm{T}-1$ showed a better cellulase production ability in the early stage of fermentation, which consequently released more glucose, the carbon source repression caused by glucose appeared earlier in the fermentation of T. asperellum strains. Carbon source repression is a common metabolic pathway in many microorganisms, especially in the lignocellulosic degrading strains. The presence of easily metabolizable and energetically favorable carbon source, such as glucose in the culture medium, results in repression of enzyme production, to ensure that the fungi would not waste too much gene expression and metabolic activity on the degradation of complex material (Aro et al. 2003). As the promoter used for the overexpression of $c b h$ gene in this research was of the endo-1,4- $\beta$-xylanase gene, which is definitely under the control of the carbon source repression (Mach et al. 1996), the changing trends of FPase activity in Fig. 6, both of the wildtype $T$. asperellum $\mathrm{T}-1$ and the transformants, were reasonable. Significantly, even under the influence of carbon source repression, the FPase activities of the mutant strains were much higher than that of the wild-type T. asperellum T-1. All the results indicated that the overexpression of one single $c b h$ gene mediated by $A$. tumefaciens AGL-1 could further improve the cellulase production of T. asperellum T-1.

\section{Conclusion}

Although T. asperellum T-1 is always used as a bio-control species, in our previous and present study, strain $\mathrm{T}-1$ is proved to be a potential decomposer of lignocellulose. And this work further indicated that the enhancement of cellulase production and lignocellulose degradation ability of T. asperellum T-1 could be promisingly feasible by overexpressing the cellulase genes using the homologous and inducible promoter Pxyl. And the genetic transformation mediated by A. tumefaciens AGL-1 could be used to effectively promote the lignocellulose degradation ability of T. asperellum T-1 and further facilitate its practical application.

Funding This study was supported by the Zhejiang Provincial Natural Science Foundation of China (LQ19D030001), the National Natural Science Foundation of China (51678531, 51878617, 41671314, 41877114), the Major State Basic Research Development Program of China (973 program) (2015CB150502), the Public Welfare Technology Application Research Project of Zhejiang Province (2016C33102), and the Project of Science and Technology Plan of Zhejiang Province (2017C32005).

The plasmid pKO1 vector was provided kindly by Prof. Jianping Lu of Zhejiang University.

Data availability All data generated or analyzed during this study are included in this published article.

\section{Compliance with ethical standards}

Conflicts of interest The authors declare that they have no conflict of interest.

Research involving human participants and/or animals N/A

Informed consent N/A

\section{References}

Alvira P, Gyalaikorpos M, Barta Z, Oliva JM, Réczey K, Ballesteros M (2013) Production and hydrolytic efficiency of enzymes from Trichoderma reesei RUTC30 using steam pretreated wheat straw as carbon source. J Chem Technol Biotechnol 88:1150-1156

Aro N, Ilmén M, Saloheimo A, Penttilä M (2003) ACEI of Trichoderma reesei is a repressor of cellulase and xylanase expression. Appl Environ Microbiol 69:56-65

Bansal N, Tewari R, Gupta JK, Soni R, Soni SK (2011) A novel strain of Aspergillus niger producing a cocktail of hydrolytic depolymerising enzymes for the production of second generation biofuels. Bioresources 6:552-569

Bech L, Herbst FA, Grell MN, Hai Z, Lange L (2015) On-site enzyme production by Trichoderma asperellum for the degradation of duckweed. Fungal Genet Biol hhttps://doi.org/10.4172/2165-8056. 1000126

Béguin P (1983) Detection of cellulase activity in polyacrylamide gels using Congo red-stained agar replicas. Anal Biochem 131:333-336

Boer WD, Folman LB, Summerbell RC, Boddy L (2010) Living in a fungal world: impact of fungi on soil bacterial niche development. FEMS Microbiol Rev 29:795-811

Bundock P, Dulk-Ras AD, Beijersbergen A et al (1995) Trans-kingdom T-DNA transfer from Agrobacterium tumefaciens to Saccharomyces cerevisiae. EMBO J 14(13):3206-3214

Daeseok L, Seunggon W, Soojung L, Yoongyo L, Yeongsuk K, Hyeunjong B (2014) Rapid saccharification for production of cellulosic biofuels. Bioresour Technol 158:239-247

Deswal D, Khasa YP, Kuhad RC (2011) Optimization of cellulase production by a brown rot fungus Fomitopsis $s p$. RCK2010 under solid state fermentation. Bioresour Technol 102:6065-6072

Ding SY, Bayer EA (2012) How does plant cell wall nanoscale architecture correlate with enzymatic digestibility? Science 338:1055-1060

Dmytruk KV, Voronovsky AY, Sibirny AA (2006) Insertion mutagenesis of the yeast Candida famata (Debaryomyces hansenii) by random integration of linear DNA fragments. Curr Genet 50:183-191

Florencio CS, Brandão FAS, Teixeira MDM, Bocca AL, Felipe MSS, Vicente VA, Fernandes L (2018) Genetic manipulation of Fonsecaea pedrosoi using particles bombardment and Agrobacterium mediated transformation. Microbiol Res 207:269 279

Gottschalk LMF, Oliveira RA, Bon EPDS (2010) Cellulases, xylanases, $\beta$-glucosidase and ferulic acid esterase produced by Trichoderma and Aspergillus act synergistically in the hydrolysis of sugarcane bagasse. Biochem Eng J 51:72-78 
Gouka RJ, Punt PJ, Ca VDH (1997) Efficient production of secreted proteins by Aspergillus: progress, limitations and prospects. Appl Microbiol Biotechnol 47:1-11

Gusakov AV (2011) Alternatives to Trichoderma reesei in biofuel production. Trends Biotechnol 29:419-425

Hui L, Wang Q, Qi S, Ma J, Fu J, Zhao Y (2014) Engineering Aspergillus oryzae A-4 through the chromosomal insertion of foreign cellulase expression cassette to improve conversion of cellulosic biomass into lipids. PLoS One 9:e108442

Inoue $\mathrm{H}$, Kitao $\mathrm{C}$, Yano $\mathrm{S}$, Sawayama S (2016) Production of $\beta$ xylosidase from Trichoderma asperellum KIF125 and its application in efficient hydrolysis of pretreated rice straw with fungal cellulase. World J Microbiol Biotechnol 32:1-10

Ji SD, Wang ZY, Fan HJ, Zhang RS, Yu ZY, Wang JJ, Liu ZH (2016) Heterologous expression of the Hsp24 from Trichoderma asperellum improves antifungal ability of Populus transformant Pdpap-Hsp24 s to Cytospora chrysosperma and Alternaria alternate. J Plant Res 129:921-933

Keswani C, Mishra S, Sarma BK, Singh SP, Singh HB (2014) Unraveling the efficient applications of secondary metabolites of various Trichoderma spp. Appl Microbiol Biotechnol 98:533-544

Kim TH, Kim JS, Sunwoo C, Lee YY (2003a) Pretreatment of corn stover by aqueous ammonia. Bioresour Technol 90:39-47

Kim YS, Seo JH, Cha HJ (2003b) Enhancement of heterologous protein expression in Escherichia coli by co-expression of nonspecific DNA-binding stress protein, Dps. Enzym Microb Technol 33:460 465

Kogo T, Yoshida Y, Koganei K, Matsumoto H, Watanabe T, Ogihara J, Kasumi T (2017) Production of rice straw hydrolysis enzymes by the fungi Trichoderma reesei and Humicola insolens using rice straw as a carbon source. Bioresour Technol 233:67-73

Kubicek CP, Mikus M, Schuster A, Schmoll M, Seiboth B (2009) Metabolic engineering strategies for the improvement of cellulase production by Hypocrea jecorina. Biotechnol Biofuels 2:19

Kubodera T, Yamashita N, Nishimura A (2002) Transformation of Aspergillus sp. and Trichoderma reesei using the pyrithiamine resistance gene (ptrA) of Aspergillus oryzae. J Agr Chem Soc Jpn 66: 404-406

Kuhad RC, Gupta R, Singh A (2011) Microbial cellulases and their industrial applications. Enzym Res 2011:1-10

Liang C, Sun G, Wu S, Liu H, Wang H (2015) Efficient transformation and expression of gfp gene in Valsa mali var. mali. World $\mathrm{J}$ Microbiol Biotechnol 31:227-235

Mach RL, Strauss J, Zeilinger S, Schindler M, Kubicek CP (1996) Carbon catabolite repression of xylanase I (xyn1) gene expression in Trichoderma reesei. Mol Microbiol 21:1273-1281

Marcello CM, Steindorff AS, Silva SPD, Silva RDN, Bataus LAM, Ulhoa CJ (2010) Expression analysis of the exo- $\beta$-1,3-glucanase from the mycoparasitic fungus Trichoderma asperellum. Microbiol Res 165:75-81

Margeot A, Hahnhagerdal B, Edlund M, Slade R, Monot F (2009) New improvements for lignocellulosic ethanol. Curr Opin Biotechnol 20: 372-380

Marx IJ, Wyk NV, Smit S, Jacobson D, Viljoen-Bloom M, Volschenk H (2013) Comparative secretome analysis of Trichoderma asperellum S4F8 and Trichoderma reesei Rut C30 during solid-state fermentation on sugarcane bagasse. Biotechnol Biofuels 6:172-172

Michielse CB, Hooykaas PJ, Ca VDH, Ram AF (2008) Agrobacteriummediated transformation of the filamentous fungus Aspergillus awamori. Nat Protoc 3:1671-1678

Nakamura M, Kuwahara H, Onoyama K, Iwai H (2012) Agrobacterium tumefaciens-mediated transformation for investigating pathogenicity genes of the phytopathogenic fungus Colletotrichum sansevieriae. Curr Microbiol 65:176-182

Nava-Cruz NY, Contreras-Esquivel JC, Aguilar-González MA, Nuncio A, Rodríguez-Herrera R, Aguilar CN (2016) Agave atrovirens fibers as substrate and support for solid-state fermentation for cellulase production by Trichoderma asperellum. Biotech 6:115

Nurul Kartini AB, Zanirun Z, Abdaziz S, Ghazali FM, Hassan MA (2012) Production of fermentable sugars from oil palm empty fruit bunch using crude cellulase cocktails with Trichoderma asperellum UPM1 and Aspergillus fumigatus UPM2 for bioethanol production. Bioresources 7:3627-3639

Raghuwanshi S, Deswal D, Karp M, Kuhad RC (2014) Bioprocessing of enhanced cellulase production from a mutant of Trichoderma asperellum RCK2011 and its application in hydrolysis of cellulose. Fuel 124:183-189

Rahman Z, Shida Y, Furukawa T, Suzuki Y, Okada H, Ogasawara W, Morikawa Y (2009) Application of Trichoderma reesei cellulase and xylanase promoters through homologous recombination for enhanced production of extracellular beta-glucosidase I. J Agr Chem Soc Jpn 73:1083-1089

Rana V, Eckard AD, Teller P, Ahring BK (2014) On-site enzymes produced from Trichoderma reesei RUT-C30 and Aspergillus saccharolyticus for hydrolysis of wet exploded corn stover and loblolly pine. Bioresour Technol 154:282-289

Rensburg EV, Haan RD, Smith J, Zyl WHV, Görgens JF (2012) The metabolic burden of cellulase expression by recombinant Saccharomyces cerevisiae Y294 in aerobic batch culture. Appl Microbiol Biotechnol 96:197-209

Rho HS, Kang S, Lee YH (2011) Agrobacterium tumefaciens-mediated transformation of the plant pathogenic fungus, Magnaporthe grisea. Mol Cell 12:407-411

Rogers SO, Bendich AJ (1994) Extraction of total cellular DNA from plants, algae and fungi. Plant Mol Biol Manual https://doi.org/10. 1007/978-94-011-0511-8 12

Selvamani S, Wahab RA, Huyop F (2015) A novel putative nonligninolytic dehalogenase activity for 3-chloropropionic acid (3CP) utilization by Trichoderma asperellum strain SD1. Malays J Microbiol 11:265-272

Sharma H, Mutharasan R (2013) HlyA gene-based sensitive detection of Listeria monocytogenes using a novel cantilever sensor. Anal Chem 85:3222-3228

Singhania RR, Patel AK, Soccol CR, Pandey A (2009) Recent advances in solid-state fermentation. Biochem Eng J 44:13-18

Sukumaran RK, Singhania RR, Mathew GM, Pandey A (2009) Cellulase production using biomass feed stock and its application in lignocellulose saccharification for bio-ethanol production. Renew Energy $34: 421-424$

Takishita K, Inagaki Y (2009) Eukaryotic origin of glyceraldehyde-3phosphate dehydrogenase genes in Clostridium thermocellum and Clostridium cellulolyticum genomes and putative fates of the exogenous gene in the subsequent genome evolution. Gene 441:22-27

Teeri TT (1997) Crystalline cellulose degradation: new insight into the function of cellobiohydrolases. Trends Biotechnol 15:160-167

Vicent et al (2004) DNA instructed displacement of histones H2A and $\mathrm{H} 2 \mathrm{~B}$ at an inducible promoter. Mol Cell 16:439-452

Vincken JP, Beldman G, Voragen A (1994) The effect of xyloglucans on the degradation of cell-wall-embedded cellulose by the combined action of cellobiohydrolase and endoglucanases from Trichoderma viride. Plant Physiol 104:99-107

Wang Q, Lin H, Shen Q, Fan X, Bai N, Zhao Y (2015) Characterization of cellulase secretion and Cre1-mediated carbon source repression in 
the potential lignocellulose-degrading strain Trichoderma asperellum T-1. PLoS One 10:e119237

Wang Q, Chen L, Yu D, Lin H, Shen Q, Zhao Y (2017) Excellent waste biomass-degrading performance of Trichoderma asperellum T-1 during submerged fermentation. Sci Total Environ 609:1329

Xiong YR et al (2018) Characterization of novel roles of a HMG-box protein PoxHmbB in biomass-degrading enzyme production by Penicillium oxalicum. Appl Microbiol Biotechnol 102:3739-3753

Zambryski P (1988) Basic processes underlying Agrobacterium-mediated DNA transfer to plant cells. Annu Rev Genet 22:1-30

Zhang Q, He G, Wang J, Cai W, Xu Y (2009) Two-stage co-hydrolysis of rice straw by Trichoderma reesei ZM4-F3 and Pseudomonas aeruginosa BSZ-07. Biomass Bioenergy 33:1464-1468
Zhang F, Zhang J, Chen L, Shi X, Lui Z, Li C (2015) Heterologous expression of ACC deaminase from Trichoderma asperellum improves the growth performance of Arabidopsis thaliana under normal and salt stress conditions. Plant Physiol Biochem 94:41-47

Znameroski EA, Coradetti ST, Roche CM, Tsai JC, Iavarone AT, Cate JH, Glass NL (2012) Induction of lignocellulose-degrading enzymes in Neurospora crassa by cellodextrins. Proc Natl Acad Sci U S A 109: 6012-6017

Publisher's note Springer Nature remains neutral with regard to jurisdictional claims in published maps and institutional affiliations. 